\title{
Synthesis and Cytotoxicity Evaluation of a Series of 3-Alkenyl-2-Hydroxy- 1,4-Naphthoquinones Obtained by an Efficient Knoevenagel Condensation
}

\author{
Cibelle C. David, ${ }^{a}$ Antonio C. S. Lins, ${ }^{a}$ Tania M. S. Silva, ${ }^{a}$ Júlia F. Campos, ${ }^{b}$ \\ Teresinha G. Silva, ${ }^{c}$ Gardenia C. G. Militão ${ }^{c}$ and Celso A. Camara ${ }^{\circledR}, a$ \\ ${ }^{a}$ Departamento de Química, Universidade Federal Rural de Pernambuco, Campus Dois Irmãos, \\ 52171-900 Recife-PE, Brazil \\ ${ }^{b}$ Centro de Tecnologias Estratégicas do Nordeste, 50740-540 Recife-PE, Brazil \\ ${ }^{c}$ Departamento de Antibióticos, Universidade Federal de Pernambuco, \\ 50670-901 Recife-PE, Brazil
}

\begin{abstract}
A modified and efficient Knoevenagel condensation procedure was developed to synthesize the title compounds using $\beta$-alanine and acetic acid as catalysts, showing good to excellent yields. We used lawsone with suitable aliphatic aldehydes including isobutyraldehyde, 3-methylbutyraldehyde, 2-ethylbutyraldehyde, phenylacetaldehyde, 2-phenyl-propionaldehyde, among others. These compounds were submitted to cytotoxic screening against three tumor cell lines presenting good to excellent cytotoxic profiles.
\end{abstract}

Keywords: 1,4-naphthoquinones, 3-alkenyl-2-hydroxy-1,4-naphthoquinones, lawsone, Knoevenagel condensation, cytotoxic evaluation

\section{Introduction}

The synthesis of 3-alkenyl-2-hydroxy-1,4-naphthoquinones has been a topic of permanent interest in Brazil and abroad. ${ }^{1,2}$ These compounds share structural features with natural lapachol (1), the most abundant quinone found in the core wood of various Bignoniaceae. Lapachol has a long tradition of use as a precursor of modified quinones, particularly for derivatives aimed at trials and screening of their multipurpose biological profiles. ${ }^{3}$

Hooker, in $1936,{ }^{4}$ published a systematic synthetic procedure for a series of 3-alkenyl-2-hydroxy1,4-naphthoquinones using lawsone (2) with suitable aliphatic aldehydes with hydrochloric acid as catalyst. Hooker used propionaldehyde, $n$-butyraldehyde, valeraldehyde, heptanaldehyde, phenylacetaldehyde and hydrocynamaldehyde (3a-f), obtaining the corresponding products in low to modest yields (23-48\%, Table 1). In this work, Hooker also pointed that he was unable to obtain the condensation product from isobutyraldehyde, and from acetaldehyde he notes that a rapid consumption of the formed product was observed. ${ }^{4}$ Fifty years later, in 1986,

*e-mail: celso.camara@ufrpe.br
Bock et al. ${ }^{5}$ published an update of this methodology (see Table 1).

Using $(R)-(+)$-citronelal $(3 \mathrm{~h})$ in Hooker's conditions, a cyclization to furnish only tetracyclic product 5 was observed (Scheme 1). ${ }^{5}$ However, changing the catalytic conditions to basic triethylamine in more polar solvents as acetonitrile or dimethylformamide (DMF), the corresponding hydroxy-naphthoquinone (3h) was obtained with 20 and $28 \%$ yield, respectively. ${ }^{5}$ These findings in the cyclization of lawsone with $(R)-(+)$-citronelal were also previously published by Ferreira et al. ${ }^{6}$ in 1982 .

In the synthesis of tetracyclic vesparione in 1987, Kopanski et al. ${ }^{7}$ developed a modified Knoevenagel procedure to obtain the deoxy-derivative of vesparione $(\mathbf{6}$, Scheme 2) with $32 \%$ yield. The procedure involved a previously explored oxidative cyclization step using 2,3-dichloro-5,6-dicyano-1,4-benzoquinone (DDQ) in both acidic or basic media. ${ }^{8,9}$ The high yield of 2-cyclopentylidenemethyl-3-hydroxy-1,4-naphthoquinone $(4 \mathrm{~m}, 94 \%)$ was obtained by the use of $\beta$-alanine/acetic acid in benzene under reflux, using only two equivalent excess of aldehyde, compared with five equivalent or higher used by Hooker. ${ }^{4}$ Dehydropyranonaphthoquinones (6) could also be obtained using modified Knoevenagel procedure by 
Table 1. Compounds 3a-l obtained by Hooker ${ }^{4}$ and Bock et al. ${ }^{5}$

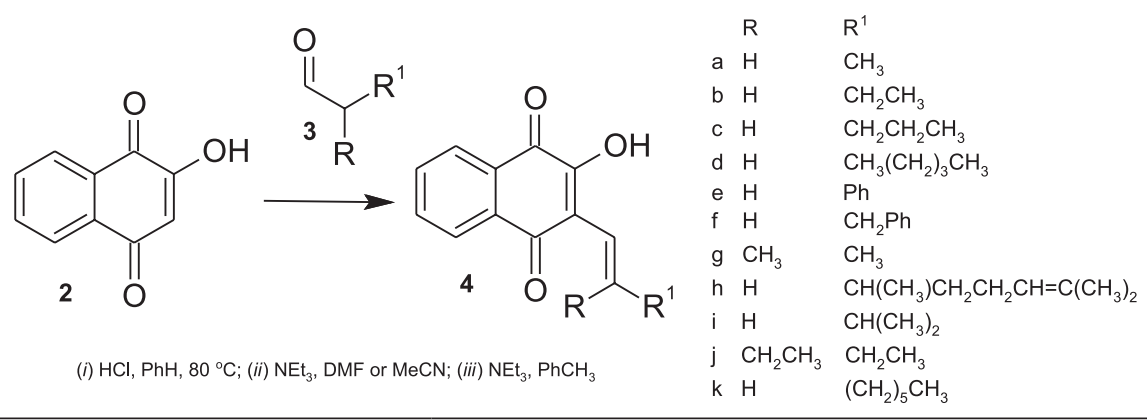

\begin{tabular}{|c|c|c|c|}
\hline entry & Aldehyde & Condition & $\begin{array}{c}\text { Product } \\
\text { (yield / \%) }\end{array}$ \\
\hline 1 & $3 a$ & (i) & $\mathbf{4 a}(23)^{4}$ \\
\hline 2 & $3 b$ & (i) & $\mathbf{4 b}(42)^{4}$ \\
\hline 3 & $3 c$ & (i) & $\mathbf{4 c}(43)^{4, \mathrm{a}}$ \\
\hline 4 & $3 d$ & (i) & $\mathbf{4 d}(35)^{4}$ \\
\hline 5 & $3 e$ & (i) & $\mathbf{4 e}(41)^{4}$ \\
\hline 6 & $3 f$ & (i) & $4 \mathbf{f}(48)^{4, \mathrm{a}}$ \\
\hline 7 & $3 g$ & (i) & $\mathbf{4 g}(-)^{4}$ \\
\hline 8 & $3 \mathrm{~h}$ & (ii) & $4 h(20-28)^{5}$ \\
\hline 9 & $3 \mathbf{i}$ & (ii) & $4 \mathbf{i}(33-36)^{5}$ \\
\hline 10 & $3 \mathbf{j}$ & (ii) and (iii) & $4 \mathbf{j}(-)^{5}$ \\
\hline 11 & $3 k$ & (ii) & $4 \mathbf{k}(30)^{5}$ \\
\hline 12 & 31 & (ii) & $4 \mathbf{l}(26)^{5}$ \\
\hline
\end{tabular}

${ }^{\mathrm{a}}$ Crude reaction product without recrystallization.<smiles>[R15]c1cccc2c(=O)c3ccccc3c(=O)c3c(c(=O)c12)[C@@H]1C[C@@H](C)CC[C@@H]1C(C)(C)O3</smiles>

Scheme 1. Tetracyclic quinone 5 from Hooker condensation using $(R)-(+)$-citronelal $(3 \mathrm{~h})$ by Ferreira et al. ${ }^{6}$

one-pot condensation-cycloaddition using $\alpha, \beta$-unsaturated aldehydes in the presence of ethylenediamine diacetate in moderate to good yields. ${ }^{10}$

Anufriev et al., ${ }^{11}$ in 1993, using a modified Hooker's methodology with methylamine hydrochloride in ethanol under reflux synthesized 3-alkenyl-2,5,8-trihydroxy1,4-naphthoquinones (8) besides 3,3'-methylenebisnaphthazarine (9) from naphthopurpurin (7, Table 2). Using few aliphatic aldehydes (propionaldehyde, isobutyraldehyde and valeraldehyde), they observed mixtures of $\mathbf{8}$ and $\mathbf{9}$ and using acetaldehyde or paraformaldehyde just dimers were formed. Using a similar approach in the selection of catalysts, Glazunov et al., ${ }^{12}$ in 2006, used methylamine hydrochloride and $p$-TsOH in refluxing benzene, obtaining modest yields of 2-hydroxy3-alkenyl-1,4-naphthoquinones by the use of propanal (48\%, conversion yield), 2-ethyl-butyraldehyde (44\%) and using naphthopurpurine (7) with propanal (16\%).

Using Bock's basic methodology ${ }^{5}$ Nagabhushana et al. ${ }^{13}$ in 2001, studied the reaction conditions for the condensation products between caproaldehyde and lawsone with triethylamine as catalyst and also under some other different conditions. Using the optimized conditions they obtained a best result yield of $43 \%$ for the desired 2-hydroxy 3-(1'-hexenyl)-1,4-naphthoquinone. ${ }^{13}$

As a part of a continuous interest of our laboratory in 


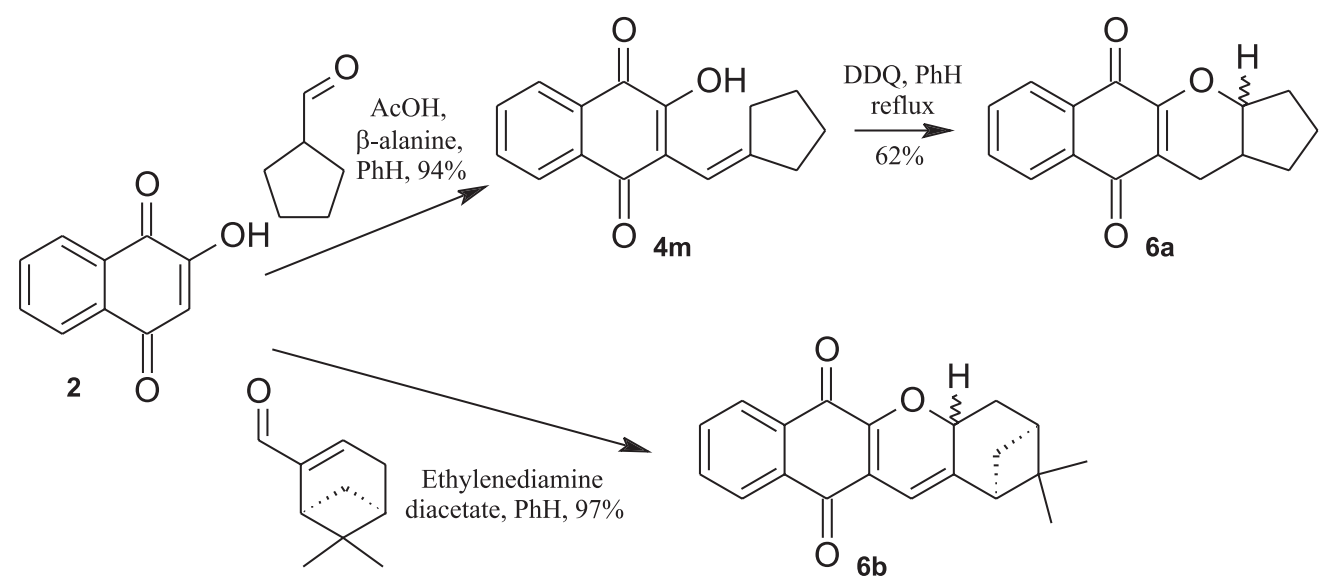

Scheme 2. Two-step synthesis of 3,4-dehydropyrano-1,4-naphthoquinones using Knoevenagel conditions in the obtention of 2-hydroxy-3-alkenyl1,4-naphthoquinone. ${ }^{7}$

Table 2. Condensation of 2-hydroxy-naphtharazin with selected aliphatic aldehydes yielding mixtures of expected alkenyls 8 and dimers $\mathbf{9}^{11}$

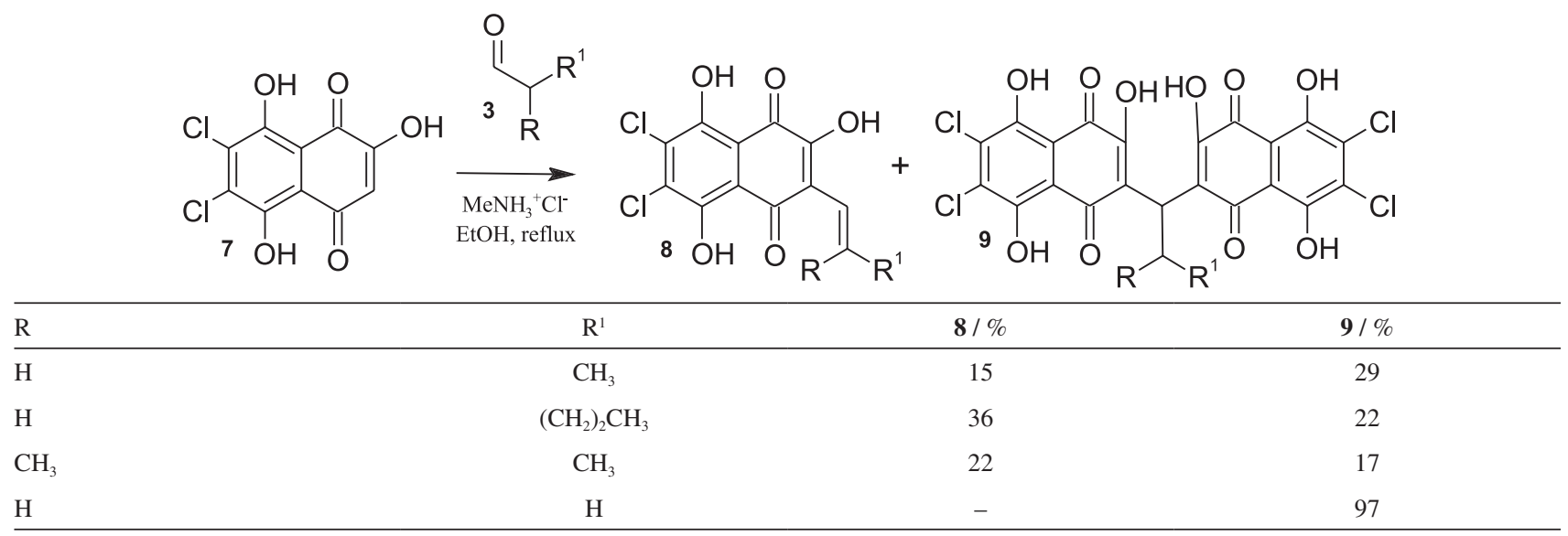

obtaining a range of 2-hydroxy-3-alkenyl-1,4-naphthoquinones (4) from suitable aliphatic aldehydes and lawsone (2) under simple Knoevenagel conditions, we chose to perform a preliminary systematic study of experimental conditions to improve product yields, but also to find a general method to synthesize those interesting compounds. As pointed above, the use of modified Knoevenagel catalysts and water scavenger could reduce undesired reactions like lawsone dimerization and side chain acid cyclization, common side reactions in this type of condensation. ${ }^{14}$ Finally, the synthesized compounds were subjected to an evaluation screening for their potentials as antitumor lead compounds against different cancer cell lines. In this study, the biological screening also included a comparison with some other available furan and pyran derived hydroxymethyl1,4-naphthoquinones obtained previously in our group by an acid catalyzed Prins cyclization of lapachol and norlapachol with paraformaldehyde and the newly corresponding acetyl derivatives.

\section{Experimental}

\section{General information}

Air- and moisture-sensitive reactions were carried out under argon atmosphere. Reagents were purchased from Sigma-Aldrich, Dinâmica or Vetec and distilled or used without further purification. Reactions were monitored by thin layer chromarography (TLC) analysis on precoated silica gel plates (Merck, Kieselgel 60 $\mathrm{GF}_{254}$ ) and compounds were visualized with UV light. Column chromatography was performed on silica gel 60 (70-230 mesh, Merck). Melting points were measured in open capillary tubes in a Quimis apparatus and are uncorrected. The infrared (IR) spectra were recorded on an IFS66 Bruker spectrophotometer using $\mathrm{KBr}$ discs or Varian Mercury 640IR with attenuated total reflectance (ATR). High resolution mass spectrometry (HRMS) analyses were performed on a matrix assisted laser desorption ionization- 
tandem time of flight (MALDI-TOF/TOF) Autoflex III 10, using positive reflected mode. Nuclear magnetic resonance (NMR) spectra were recorded on a Varian Unity Plus-400 spectrometer $\left({ }^{1} \mathrm{H}\right.$ at $400 \mathrm{MHz}$ and ${ }^{13} \mathrm{C}$ at $\left.100 \mathrm{MHz}\right)$, $200 \mathrm{MHz}$ Varian Mercury or Anasazi $\left(90 \mathrm{MHz}\right.$ for ${ }^{1} \mathrm{H}$ and 22.5 MHz for ${ }^{13} \mathrm{C}$ ), using $\mathrm{CDCl}_{3}$ or dimethyl sulfoxide- $d_{6}$ (DMSO- $d_{6}$ ) as solvents, and calibrated for the solvent signal. Chemical shifts are expressed in parts per million (ppm) and coupling constants are given in $\mathrm{Hz}$. Assignments are based on correlation spectroscopy (COSY) and heteronuclear single quantum coherence (HSQC) experiments.

\section{Synthesis}

The compounds 10a ( $\beta$-lapachone) and 10b (nor- $\beta$-lapachone) were obtained as described by literature methods from lapachol and norlapachol, respectively. ${ }^{15}$

Synthesis of 3-alkenyl-2-hydroxy-1,4-naphthoquinones compounds (4)

Method A: in a flask, it was added lawsone 2 (0.2 g, $1.2 \mathrm{mmol}), \beta$-alanine $(0.03 \mathrm{~g}, 0.33 \mathrm{mmol})$ and toluene $(40 \mathrm{~mL})$, followed by glacial acetic acid $(0.017 \mathrm{~g}$, $0.28 \mathrm{mmol}$ ) and the corresponding aldehyde $(2.3 \mathrm{mmol})$. The reaction system was kept under reflux using a Dean-Stark apparatus. The reaction was monitored by TLC for about $1 \mathrm{~h}$. The solvent was removed and the compound was purified by crystallization in $\mathrm{EtOH} / \mathrm{H}_{2} \mathrm{O}(\mathbf{4 e}, \mathbf{4 g}, \mathbf{4 i}$, $\mathbf{4 j}$ ) or by column chromatography with silica gel and hexanes:ethyl acetate 90:10 as eluent (4a, 4b, 4c, 4p).

Method B: in a flask, it was added lawsone $(2,0.2 \mathrm{~g}$, $1.2 \mathrm{mmol}), \beta$-alanine $(0.06 \mathrm{~g}, 0.67 \mathrm{mmol})$ and toluene $(40 \mathrm{~mL})$, followed by glacial acetic acid $(0.034 \mathrm{~g}$, $0.56 \mathrm{mmol})$ and the corresponding aldehyde $(2.3 \mathrm{mmol})$. The reaction system was kept under reflux using Dean-Stark apparatus. Inspection of the progress of the reaction was made by TLC for about $1 \mathrm{~h}$. The solvent was removed and the compound was purified by column chromatography with silica gel and hexanes:ethyl acetate 90:10 as eluent.

2-Hydroxy-3-propenyl-[1,4]naphthoquinone $\left(\mathrm{C}_{13} \mathrm{H}_{10} \mathrm{O}_{3}\right)(4 a)$

Orange solid; mp $131-133{ }^{\circ} \mathrm{C}$ (lit. 135.2-135.7 $\left.{ }^{\circ} \mathrm{C}\right){ }^{4}$ ${ }^{1} \mathrm{H}$ NMR (400 MHz, $\left.\mathrm{CDCl}_{3}\right) \delta 8.11(\mathrm{dd}, 1 \mathrm{H}, J 7.8,1.2 \mathrm{~Hz})$, 8.05 (dd, 1H, J 7.4, 1.6 Hz), 7.74 (dt, 1H, J 7.8, 1.6 Hz), 7.67 (dt, 1H, J 7.8, 1.2 Hz), 7.07 (dq, 1H, J 16.0, 7.0 Hz), 6.62 (dq, 1H, J 16.0, 1.6 Hz), 1.98 (dd, 3H, J 7.0, 1.6 Hz); ${ }^{13} \mathrm{C}$ NMR attached proton test (APT) $\left(100 \mathrm{MHz}, \mathrm{CDCl}_{3}\right)$ $\delta$ 184.2, 181.4, 151.2, 138.8, 134.8, 133.0, 132.7, 129.4, 127.0, 125.9, 119.9, 118.6, 20.5; IR (ATR) $v_{\max } / \mathrm{cm}^{-1} 3227$, 2977, 1654, 1591, 1458, 1365, 1260; HRMS (MALDI) calcd.: 215.0703, found: 215.0713 .
2-Hydroxy-3-butenyl-[1,4]naphthoquinone $\left(\mathrm{C}_{14} \mathrm{H}_{12} \mathrm{O}_{3}\right)(\mathbf{4 b})$

Orange solid; mp $99{ }^{\circ} \mathrm{C}$ (lit. $\left.101.5{ }^{\circ} \mathrm{C}\right) ;{ }^{4}{ }^{1} \mathrm{H}$ NMR $\left(200 \mathrm{MHz}, \mathrm{CDCl}_{3}\right) \delta 8.09$ (ddd, 1H, J 7.4, 1.4, $0.8 \mathrm{~Hz}$ ), 8.05 (ddd, 1H, J 7.4, 1.4, 0.6 Hz), 7.81 (s, 1H), 7.80 (dt, 1H, J 7.4, $1.4 \mathrm{~Hz}), 7.70(\mathrm{dt}, 1 \mathrm{H}, J 7.6,1.8 \mathrm{~Hz}), 7.30$ (dt, $1 \mathrm{H}, J 16.2,6.8 \mathrm{~Hz}), 6.70$ (dt, 1H, J 16.2, $1.6 \mathrm{~Hz}), 2.29$ (dq, $2 \mathrm{H}, J 7.2,1.4 \mathrm{~Hz}), 1.19(\mathrm{t}, 3 \mathrm{H}, J 7.4 \mathrm{~Hz}) ;{ }^{13} \mathrm{C} \mathrm{NMR}$ (APT) $\left(50 \mathrm{MHz}, \mathrm{CDCl}_{3}\right) \delta 184.3,181.3,151.2,145.4,134.8$, 133.0, 132.6, 129.4, 127.0, 125.9, 118.7, 117.7, 28.0, 13.3; ${ }^{11}$ IR (KBr) $v_{\max } / \mathrm{cm}^{-1} 3330,3072,2964,2933,2876,1652$, 1592, 1459, 1372, 1341, 1263; HRMS (MALDI) calcd.: 229.0859, found: 229.0851 .

2-Hydroxy-3-pentenyl-[1,4]naphthoquinone $\left(\mathrm{C}_{15} \mathrm{H}_{14} \mathrm{O}_{3}\right)(4 \mathrm{c})$

Orange solid; mp 95-98 ${ }^{\circ} \mathrm{C}$ (lit. 98-98.5 $\left.{ }^{\circ} \mathrm{C}\right) ;{ }^{4}{ }^{1} \mathrm{H}$ NMR $\left(200 \mathrm{MHz} \mathrm{CDCl}_{3}\right) \delta 8.08(\mathrm{dd}, 1 \mathrm{H}, J 7.2,1.6 \mathrm{~Hz}), 8.01$ (dd, 1H, J 7.4, 1.8 Hz), 7.70 (dt, 1H, J 7.6, $1.8 \mathrm{~Hz}), 7.66$ (s, 1H), $7.62(\mathrm{dt}, 1 \mathrm{H}, J 7.4,1.4 \mathrm{~Hz}), 7.03(\mathrm{dt}, 1 \mathrm{H}, J$ 16.2, $7.0 \mathrm{~Hz}$ ), 6.57 (dt, 1H, J 16.4, 1.2 Hz), 2.24 (dq, 2H, J 7.2, $1.2 \mathrm{~Hz}), 1.49$ (sex, 2H, J 7.2 Hz), 0.93 (t, 3H, J 7.4 Hz); ${ }^{11}$ ${ }^{13} \mathrm{C} \mathrm{NMR}\left(50 \mathrm{MHz}, \mathrm{CDCl}_{3}\right) \delta 184.3,181.4,151.2,144.0$, 134.8, 133.0, 132.6, 129.4, 127.0, 125.9, 118.8, 118.7, 37.1, 22.3, 13.8; IR (KBr) $v_{\max } / \mathrm{cm}^{-1} 3454,3330,2959$, 2930, 2869, 1652, 1632, 1607, 1460, 1375, 1278; HRMS (MALDI) calcd.: 243.1016, found: 243.1001.

2-Hydroxy-3-styryl-[1,4]naphthoquinone $\left(\mathrm{C}_{18} \mathrm{H}_{12} \mathrm{O}_{3}\right)(4 \mathrm{e})$

Orange crystals; mp 163-165 ${ }^{\circ} \mathrm{C}$ (lit. 167-168 ${ }^{\circ} \mathrm{C}$ ) $;{ }^{4}$ ${ }^{1} \mathrm{H}$ NMR $\left(200 \mathrm{MHz}, \mathrm{CDCl}_{3}\right) \delta 8.13(\mathrm{ddd}, 1 \mathrm{H}, J$ 7.4, 1.6, $0.4 \mathrm{~Hz}$ ), 8.04 (ddd, 1H, J 7.0, 1.4, $0.6 \mathrm{~Hz}), 7.93$ (d, 1H, $J 17 \mathrm{~Hz}), 7.73(\mathrm{dt}, 1 \mathrm{H}, J 7.2,1.4 \mathrm{~Hz}), 7.65(\mathrm{dt}, 1 \mathrm{H}, J 7.2$, $1.6 \mathrm{~Hz}), 7.57$ (ddd, 2H, J 7.6, 1.6, 0.4 Hz), 7.36 (d, 1H, $J 16.6 \mathrm{~Hz}), 7.36(\mathrm{~m}, 3 \mathrm{H}) ;{ }^{13} \mathrm{C} \mathrm{NMR}$ (APT) $\left(50 \mathrm{MHz}, \mathrm{CDCl}_{3}\right)$ $\delta$ 184.0, 180.9, 151.8, 139.1, 137.7, 134.8, 133.1, 132.6, $129.5,128.6,128.5,127.1,127.0,125.9,118.6,117.3$; IR (KBr) $v_{\max } / \mathrm{cm}^{-1} 3312,3061,3027,2929,1651,1592$, 1451, 1372, 1262; HRMS (MALDI) calcd.: 277.0859, found: 277.0857 .

2-Hydroxy-3-(3-phenyl-propenyl)-[1,4]naphthoquinone $\left(\mathrm{C}_{19} \mathrm{H}_{14} \mathrm{O}_{3}\right)$ (4f)

Orange crystals; mp $121-124^{\circ} \mathrm{C}$ (lit. $\left.140.5-141.5^{\circ} \mathrm{C}\right) ;{ }^{4}$ ${ }^{1} \mathrm{H}$ NMR (400 MHz, $\mathrm{CDCl}_{3}$ ) $\delta 8.11$ (ddd, 1H, J 7.6, 7.1, 1.2, $0.5 \mathrm{~Hz}), 8.05$ (ddd, $1 \mathrm{H}, J 7.3,1.5,0.5 \mathrm{~Hz}), 7.74$ (dt, 1H, J 7.6, 1.4 Hz), 7.67 (ddt, 1H, J 7.6, 7.4, 1.2 Hz), 7.33-7.16 $(\mathrm{m}, 6 \mathrm{H}), 6.72(\mathrm{dt}, 1 \mathrm{H}, J 16.3,1.5 \mathrm{~Hz}), 3.63(\mathrm{dd}, 2 \mathrm{H}, J 7.1$, $1.2 \mathrm{~Hz}) ;{ }^{13} \mathrm{C}$ NMR (APT) (100 MHz, $\left.\mathrm{CDCl}_{3}\right) \delta 184.1,181.3$, $151.5,141.6,139.6,135.0,133.1,132.7,129.4,128.7$, $128.5,127.0,126.3,126.0,119.8,118.3,41.3$; IR (KBr) $v_{\max } / \mathrm{cm}^{-1} 3280,3063,2926,2856,1651,1597,1459,1380$, 1257; HRMS (MALDI) calcd.: 290.0937, found: 290.0956. 
2-Hydroxy-3-(2-methyl-propenyl)-[1,4]naphthoquinone $\left(\mathrm{C}_{14} \mathrm{H}_{12} \mathrm{O}_{3}\right)(\mathbf{4 g})$

Orange crystals; mp $114-117{ }^{\circ} \mathrm{C}$ (lit. $119-120{ }^{\circ} \mathrm{C}$ ) ${ }^{16}$ ${ }^{1} \mathrm{H}$ NMR $\left(200 \mathrm{MHz}\right.$, DMSO- $\left.d_{6}\right) \delta$ 8.05-7.96 (m, 2H), 7.90-7.76 (m, 2H), $5.87(\mathrm{~m}, 1 \mathrm{H}), 1.91(\mathrm{~d}, 3 \mathrm{H}, J 1.2 \mathrm{~Hz})$, $1.58(\mathrm{~d}, 3 \mathrm{H}, J 0.8 \mathrm{~Hz}) ;{ }^{13} \mathrm{C}$ NMR (APT) $(50 \mathrm{MHz}$, DMSO- $\left.d_{6}\right) \delta 185.2,182.1,155.0,141.0,135.5,134.1$, $133.0,131.1,126.8,126.6,121.5,116.0,27.0,22.4$; IR (KBr) $v_{\max } / \mathrm{cm}^{-1} 3363,3074,2969,2927,2863$, 1647, 1592, 1453, 1377, 1275; HRMS (MALDI) calcd.: 229.0859, found: 229.0865 .

2-Hydroxy-3-(3-methylbut-1-enyl)-[1,4]naphthoquinone $\left(\mathrm{C}_{15} \mathrm{H}_{14} \mathrm{O}_{3}\right)(4 \mathrm{i})$

Red crystals; mp $107-110{ }^{\circ} \mathrm{C}$ (lit. $\left.118-119{ }^{\circ} \mathrm{C}\right) ; ;^{17}$ ${ }^{1} \mathrm{H}$ NMR $\left(200 \mathrm{MHz}, \mathrm{CDCl}_{3}\right) \delta 8.08$ (ddd, $1 \mathrm{H}, J 7.2,1.8$, $0.8 \mathrm{~Hz}), 8.01(\mathrm{dd}, 1 \mathrm{H}, J 7.4,1.4 \mathrm{~Hz}), 7.77(\mathrm{~s}, 1 \mathrm{H}), 7.70$ (dt, 1H, J 7.6, $1.8 \mathrm{~Hz}), 7.62(\mathrm{dt}, 1 \mathrm{H}, J 7.4,1.4 \mathrm{~Hz}), 7.02$ (dd, 1H, J 16.4, 7.2 Hz), 6.57 (dd, 1H, J 16.4, 1.2 Hz), $2.51(\mathrm{~m}, 1 \mathrm{H}), 1.09(\mathrm{~d}, 6 \mathrm{H}, J 6.6 \mathrm{~Hz}) ;{ }^{13} \mathrm{C}$ NMR (APT) $\left(50 \mathrm{MHz}, \mathrm{CDCl}_{3}\right) \delta 184.3,181.3,151.2,150.5,134.9$, $133.0,132.7,129.4,127.0,125.9,118.7,115.9,33.4$, $22.2 ;{ }^{11} \mathrm{IR}(\mathrm{KBr}) v_{\max } / \mathrm{cm}^{-1} 3323,2958,2926,2867,1656$, 1631, 1592, 1461, 1372, 1279; HRMS (MALDI) calcd.: 243.1016, found: 243.1030 .

2-(2-Ethyl-but-1-enyl)-3-hydroxy-[1,4]naphthoquinone $\left(\mathrm{C}_{16} \mathrm{H}_{16} \mathrm{O}_{3}\right)(4 \mathrm{j})$

Yellow crystals; mp 99-100 ${ }^{\circ} \mathrm{C}$ (lit. 91-93 $\left.{ }^{\circ} \mathrm{C}\right) ;{ }^{1} \mathrm{H}$ NMR $\left(400 \mathrm{MHz}, \mathrm{CDCl}_{3}\right) \delta 8.12$ (dd, 1H, J 7.6, 1.4 Hz), 8.09 (dd, $1 \mathrm{H}, J$ 7.6, $1.4 \mathrm{~Hz}), 7.75(\mathrm{dt}, 1 \mathrm{H}, J$ 7.6, $1.2 \mathrm{~Hz}), 7.69(\mathrm{dt}$, $1 \mathrm{H}, J 7.6,1.2 \mathrm{~Hz}), 7.48(\mathrm{sl}, 1 \mathrm{H}), 5.90(\mathrm{~s}, 1 \mathrm{H}), 2.30(\mathrm{dq}, 2 \mathrm{H}$, $J 7.4,1.4 \mathrm{~Hz}), 2.05(\mathrm{q}, 2 \mathrm{H}, J 7.4 \mathrm{~Hz}), 1.16(\mathrm{t}, 3 \mathrm{H}, J 7.4 \mathrm{~Hz})$, $1.01(\mathrm{t}, 3 \mathrm{H}, J 7.6 \mathrm{~Hz}) ;{ }^{13} \mathrm{C} \mathrm{NMR}(\mathrm{APT})\left(100 \mathrm{MHz}, \mathrm{CDCl}_{3}\right)$ $\delta$ 184.7, 181.5, 153.6, 151.4, 134.9, 133.0, 132.9, 129.5, 126.9, 126.0, 121.2, 111.1, 28.9, 26.4, 12.6, 12.1; IR (KBr) $v_{\max } / \mathrm{cm}^{-1} 3439,2965,2935,2876,1663,1643,1593,1459$, 1332, 1273; HRMS (MALDI) calcd.: 257.1172, found: 257.1181.

2-Hydroxy-3-hexenyl-[1,4]naphthoquinone $\left(\mathrm{C}_{16} \mathrm{H}_{16} \mathrm{O}_{3}\right)(4 \mathrm{p})$

Orange solid; mp 83-85 ${ }^{\circ} \mathrm{C}$ (lit. 82-83 ${ }^{\circ} \mathrm{C}$ ) $;{ }^{4}{ }^{1} \mathrm{H}$ NMR $\left(90 \mathrm{MHz}, \mathrm{CDCl}_{3}\right) \delta 8.09(\mathrm{dd}, 1 \mathrm{H}, J 6.9,2.2 \mathrm{~Hz}), 8.02$ (dd, 1H, J 6.9, 2.2 Hz), 7.82-7.53 (m, 2H), $7.08(\mathrm{dt}, 1 \mathrm{H}$, $J$ 16.4, $6.9 \mathrm{~Hz}), 6.58(\mathrm{dt}, 1 \mathrm{H}, J 16.1,1.1 \mathrm{~Hz}), 2.30(\mathrm{dq}, 2 \mathrm{H}$, $J$ 6.6, 1.1, $0.7 \mathrm{~Hz}), 1.64-1.18(\mathrm{~m}, 4 \mathrm{H}), 1.00-0.84(\mathrm{~m}, 3 \mathrm{H}$, $J 6.6 \mathrm{~Hz}) ;{ }^{13} \mathrm{C}$ NMR $\left(22.73 \mathrm{MHz}, \mathrm{CDCl}_{3}\right) \delta 184.7,181.9$, 151.8, 144.6, 135.3, 133.4, 127.5, 126.4, 119.2, 35.2, 31.7, 22.9, 14.4; IR (KBr) $v_{\max } / \mathrm{cm}^{-1} 3449,3268,2959,2927$, 2858, 1654, 1632, 1608, 1593, 1458, 1371, 1265; HRMS (MALDI) calcd.: 257.1172, found: 257.1188.
2-Hydroxy-3-(2-phenyl-propenyl)-[1,4]naphthoquinone $\left(\mathrm{C}_{19} \mathrm{H}_{14} \mathrm{O}_{3}\right)(\mathbf{4 q})$

Orange crystals; $\mathrm{mp} 142-144{ }^{\circ} \mathrm{C}$ (lit. 141.2-143.6 $\left.{ }^{\circ} \mathrm{C}\right) ;^{18}$ ${ }^{1} \mathrm{H}$ NMR $\left(400 \mathrm{MHz}, \mathrm{CDCl}_{3}\right) \delta 8.15$ (dd, $\left.1 \mathrm{H}, J 7.6,1.4 \mathrm{~Hz}\right)$, 8.11 (dd, $1 \mathrm{H}, J 7.6,1.5 \mathrm{~Hz}), 7.77$ (ddt, $1 \mathrm{H}, J 7.6,1.5$, $0.7 \mathrm{~Hz}$ ), 7.70 (ddt, 1H, J 7.6, 1.5, 0.7 Hz), $7.58(\mathrm{~m}, 2 \mathrm{H})$, 7.38-7.27 (m, 3H), $6.62(\mathrm{~m}, 1 \mathrm{H}), 2.08(\mathrm{~m}, 3 \mathrm{H}) ;{ }^{13} \mathrm{C} \mathrm{NMR}$ (APT) $\left(100 \mathrm{MHz}, \mathrm{CDCl}_{3}\right) \delta 184.5,181.4,151.3,144.1$, $142.5,135.0,133.1,133.0,129.6,128.3,127.8,127.0$, 126.2, 126.2, 120.8, 116.0, 19.5; IR (KBr) $v_{\max } / \mathrm{cm}^{-1} 3374$, 3081, 2957, 2929, 2859, 1664, 1638, 1595, 1459, 1326, 1276, 1255; HRMS (MALDI) calcd.: 290.0937, found: 290.0933.

2-Cyclopent-1-enyl-3-hydroxy-[1,4]naphthoquinone $\left(\mathrm{C}_{15} \mathrm{H}_{12} \mathrm{O}_{3}\right)(\mathbf{4 r})$

Orange crystals; mp $111-113{ }^{\circ} \mathrm{C} ;{ }^{1} \mathrm{H}$ NMR $(400 \mathrm{MHz}$, $\left.\mathrm{CDCl}_{3}\right) \delta 8.10$ (ddd, $1 \mathrm{H}, J 7.8,1.2,0.8 \mathrm{~Hz}$ ), 8.05 (ddd, $1 \mathrm{H}$, $J$ 7.8, 1.2, $0.8 \mathrm{~Hz}$ ), 7.73 (ddt, 1H, J 7.8, 1.6, $0.8 \mathrm{~Hz}$ ), 7.65 (ddt, $1 \mathrm{H}, J 7.4,1.6,0.8 \mathrm{~Hz}), 6.53(\mathrm{~m}, 1 \mathrm{H}), 2.85(\mathrm{ddd}, 1 \mathrm{H}$, $J$ 7.4, 4.3, $2.0 \mathrm{~Hz}$ ), 2.83 (ddd, $1 \mathrm{H}, J$ 7.4, 4.3, $2.0 \mathrm{~Hz}$ ), 2.55 (ddd, 1H, J 7.0, 4.7, $2.4 \mathrm{~Hz}$ ), 2.53 (ddd, 1H, J 7.0, 4.7, $2.4 \mathrm{~Hz}$ ), 1.94 (qui, $2 \mathrm{H}, J 7.8,7.4 \mathrm{~Hz}$ ); ${ }^{13} \mathrm{C}$ NMR (APT) $\left(100 \mathrm{MHz}, \mathrm{CDCl}_{3}\right) \delta 184.1,181.5,151.7,138.9,134.9$, 133.7, 133.2, 132.8, 129.1, 127.0, 125.8, 119.7, 35.6, 33.6, 23.4; IR (KBr) $v_{\max } / \mathrm{cm}^{-1} 3325,3081,2962,2930,2873$, 1651, 1591, 1461, 1365, 1245; HRMS (MALDI) calcd.: 240.0781, found: 240.0780 .

\section{Synthesis of $\mathbf{1 0 b}$ and $\mathbf{1 1 b}$}

In a preheated flask filled with formic acid $(25 \mathrm{~mL})$, it was added paraformaldehyde $(1.32 \mathrm{~g}, 44.3 \mathrm{mmol})$ followed by corresponding lapachol or norlapachol $(22 \mathrm{mmol})$. The reaction was heated for $2 \mathrm{~h}$ at $90{ }^{\circ} \mathrm{C}$, and water $(50 \mathrm{~mL})$ was added and the mixture was kept under reflux for $12 \mathrm{~h}$. The reaction mixture was cooled, neutralized with $\mathrm{Na}_{2} \mathrm{CO}_{3}$ saturated solution and the resulting precipitate was submitted to vacuum filtration. The compounds were purified by column chromatography with silica gel using mixtures of dichlorometane:hexanes and dichloromethane:ethyl acetate with increasing polarity.

3-Hydroxymethyl-2,2-dimethyl-3,4-dihydro-2 $\mathrm{H}$-benzo [h]chromene-5,6-dione $\left(\mathrm{C}_{16} \mathrm{H}_{16} \mathrm{O}_{4}\right)(\mathbf{1 0 b})$

Orange crystals (51\%); mp $147-150{ }^{\circ} \mathrm{C}$; ${ }^{1} \mathrm{H}$ NMR $\left(200 \mathrm{MHz}, \mathrm{CDCl}_{3}\right) \delta 7.96(\mathrm{dd}, 1 \mathrm{H}, J 7.6,1.2 \mathrm{~Hz}), 7.74(\mathrm{dd}$, $1 \mathrm{H}, J 7.6,1.0 \mathrm{~Hz}), 7.59$ (ddd, $1 \mathrm{H}, J 8,7.6 \mathrm{~Hz}), 7.67$ (dd, $1 \mathrm{H}$, $J 8,7.6 \mathrm{~Hz}), 3.82(\mathrm{dd}, 1 \mathrm{H}, J 11,5.2 \mathrm{~Hz}), 3.60(\mathrm{dd}, 1 \mathrm{H}, J$, $11 \mathrm{~Hz}), 3.01$ (br, 1H), $2.74(\mathrm{dd}, 1 \mathrm{H}, J 5.6,17.6 \mathrm{~Hz}), 2.27$ (dd, 1H, J 17.6, $11 \mathrm{~Hz}), 2.01(\mathrm{~m}, 1 \mathrm{H}, J 5.2,5.6,7,11 \mathrm{~Hz})$, 1.56 (s, 3H), 1.30 (s, 3H); ${ }^{13} \mathrm{C}$ NMR (APT) $(50.3 \mathrm{MHz}$, 
$\left.\mathrm{CDCl}_{3}\right) \delta 179.7,178.4,161.9,134.8,132.1,130.7,129.9$, 128.4, 124.1, 112.4, 81.7, 71.0, 62.6, 27.5, 21.9, 19.6; IR (KBr) $v_{\max } / \mathrm{cm}^{-1} 3072,2982,1737,1695,1607,1572,1457$, 1392, 1293, 1232, 1132, 1092, 1034, 984, 934; HRMS (MALDI) calcd.: 273.1121, found: 273.1119.

3-Hydroxymethyl-2,2-dimethyl-2,3-dihydro-naphtho [1,2-b]furan-4,5-dione $\left(\mathrm{C}_{15} \mathrm{H}_{14} \mathrm{O}_{4}\right)(\mathbf{1 1 b})$

Dark red crystals $(76 \%)$; mp $122-124{ }^{\circ} \mathrm{C} ;{ }^{1} \mathrm{H}$ NMR (400 MHz, $\left.\mathrm{CDCl}_{3}\right) \delta 8.03(\mathrm{~d}, 1 \mathrm{H}, J 7.5 \mathrm{~Hz}), 7.66(\mathrm{~m}, 2 \mathrm{H})$, $7.58(\mathrm{~m}, 1 \mathrm{H}), 4.03(\mathrm{sl}, 1 \mathrm{H}), 3.85(\mathrm{dd}, 1 \mathrm{H}, J 11,8.4 \mathrm{~Hz})$, 3.78 (dd, 1H, $J 11,4.3 \mathrm{~Hz}$ ), 3.35 (dd, 1H, $J 8.3,4.6 \mathrm{~Hz}$ ), 1.65 (s, 3H), 1.47 (s, 3H); ${ }^{13} \mathrm{C}$ NMR (APT) $(100 \mathrm{MHz}$, $\left.\mathrm{CDCl}_{3}\right) \delta 181.0,176.4,170.5,134.6,132.4,130.7,129.2$, 127.3, 124.9, 117.4, 95.4, 61.3, 52.4, 29.1, 22.2; IR (KBr) $v_{\max } / \mathrm{cm}^{-1} 3362,2968,2926,1645,1591,1456,1376,1343$, 1275, 1213, 1163; HRMS (MALDI) calcd.: 259.0965, found: 259.0961 .

\section{Synthesis of $10 \mathrm{c}$ and $11 \mathrm{c}$}

In a round bottom flask with $10 a$ or $11 a(200 \mathrm{mg})$, it was added acetic anhydride $(1 \mathrm{~mL}, 10.6 \mathrm{mmol})$ followed by pyridine ( $1 \mathrm{~mL}, 12.4 \mathrm{mmol})$. After $2.5 \mathrm{~h}$, after TLC inspection, the product was precipitated in ice-water and submitted to vacuum filtration and column chromatography with silica gel using mixtures of dichlorometane:hexanes and dichloromethane:ethyl acetate with increasing polarity.

3-[(Acetyloxy)methyl]-2,2-dimethyl-3,4-dihydro-2H-benzo [h]chromene-5,6-dione $\left(\mathrm{C}_{18} \mathrm{H}_{18} \mathrm{O}_{5}\right)(\mathbf{1 0 c})$

Purified by chromatography using silica gel with hexanes:ethyl acetate 6:4 yielding an yellow solid (54\%); mp 91-92 ${ }^{\circ} \mathrm{C} ;{ }^{1} \mathrm{H}$ NMR $\left(400 \mathrm{MHz}, \mathrm{CDCl}_{3}\right) \delta 7.97(\mathrm{dd}, 1 \mathrm{H}$, $J$ 7.8, $1.6 \mathrm{~Hz}), 7.73(\mathrm{dd}, 1 \mathrm{H}, J 7.8,1.6 \mathrm{~Hz}), 7.59(\mathrm{dt}, 1 \mathrm{H}$, $J$ 7.8, $1.6 \mathrm{~Hz}), 7.45(\mathrm{dt}, 1 \mathrm{H}, J 7.4,1.2 \mathrm{~Hz}), 4.23(\mathrm{dd}, 1 \mathrm{H}$, $J$ 11.4, $5.1 \mathrm{~Hz}), 3.88(\mathrm{dd}, 1 \mathrm{H}, J 11.3,7.4 \mathrm{~Hz}), 2.74(\mathrm{dd}$, 1H, $J 17.6,5.4 \mathrm{~Hz}$ ), 2.28 (dd, 1H, $J 17.6,9.4 \mathrm{~Hz}), 2.15$ (m, 1H), 2.02 (s, 3H), 1.54 (s, 3H), $1.32(\mathrm{~s}, 3 \mathrm{H}) ;{ }^{13} \mathrm{C}$ NMR (APT) $\left(100 \mathrm{MHz}, \mathrm{CDCl}_{3}\right) \delta 179.3,178.2,170.6,134.7$, $130.7,129.9,128.4,124.0,111.8,80.6,64.0,39.2,27.2$, 21.9, 20.7, 19.8; IR (KBr) $v_{\max } / \mathrm{cm}^{-1} 3068,2975,1714$, 1643, 1614, 1587, 1488, 1403, 1334, 1275, 1177, 1107, 1076; HRMS (MALDI) calcd.: 315.1227, found: 315.1229.

3-[(Acetyloxy)methyl]-2,2-dimethyl-2,3-dihydro-naphtho [1,2-b]furan-4,5-dione $\left(\mathrm{C}_{17} \mathrm{H}_{16} \mathrm{O}_{5}\right)(11 \mathrm{c})$

Purified by recristallization from $\mathrm{EtOH} / \mathrm{H}_{2} \mathrm{O}$ yielding brownish crystals (86\%); mp 140-141 ${ }^{\circ} \mathrm{C} ;{ }^{1} \mathrm{H}$ NMR $\left(400 \mathrm{MHz}, \mathrm{CDCl}_{3}\right) \delta 8.08(\mathrm{~d}, 1 \mathrm{H}, J 7.2 \mathrm{~Hz}), 7.61(\mathrm{~m}$, $3 \mathrm{H}), 4.51(\mathrm{dd}, 1 \mathrm{H}, J 11.2,4.0 \mathrm{~Hz}), 4.24(\mathrm{dd}, 1 \mathrm{H}, J 11.6$, $9.2 \mathrm{~Hz}$ ), 3.49 (dd, 1H, J 9.2, $4.0 \mathrm{~Hz}$ ), 2.04 (s, 3H), 1.59 (s, 3H), 1.58 (s, 3H); ${ }^{13} \mathrm{C}$ NMR (APT) (100 MHz, $\mathrm{CDCl}_{3}$ ) $\delta 180.9,175.4,170.5,169.0,134.5,132.2,130.9,129.4$, 127.5, 124.8, 114.3, 94.7, 61.5, 47.9, 29.6, 22.2, 20.8; IR $(\mathrm{KBr}) v_{\max } / \mathrm{cm}^{-1} 2099,2901,1734,1695,1611,1567,1490$, 1402, 1379, 1243, 1120, 1082; HRMS (MALDI) calcd.: 301.1071, found: 301.1074 .

\section{In vitro citotoxicity assay}

The human lung carcinoma cell line (NCI-H292), human larynx carcinoma cell line (HEP-2) and breast adenocarcinoma (MCF-7) were purchased from the Adolfo Lutz Institute, São Paulo, Brazil. A Dulbecco's Modified Eagle's medium (DMEM), enriched with 10\% of fetal bovine serum, $1 \%$ of $L$-glutamine and $1 \%$ of antibiotics (penicillin and streptomycin), was used for cell cultivation and to perform the tests. The cytotoxic activity was investigated using the 3-(4,5-dimethylthiazole2-yl)-2,5-diphenyltetrazolium bromide (MTT) assay. ${ }^{19}$ Cell suspensions were diluted to $10^{5}$ cells $\mathrm{mL}^{-1}$, suitably prepared and distributed in plates of culture with 96 wells $\left(225 \mu \mathrm{L}\right.$ in each well), then incubated at $37{ }^{\circ} \mathrm{C}$ in a humid atmosphere with $5 \%$ of $\mathrm{CO}_{2}$. After $24 \mathrm{~h}, 25 \mu \mathrm{L}$ of either the synthesized compounds or the reference drugs (doxorubicine and cisplatin) were added to each well. The plates were incubated again at $37{ }^{\circ} \mathrm{C}$ for $72 \mathrm{~h}$. Then, $25 \mu \mathrm{L}$ of MTT solution ( $5 \mathrm{mg} \mathrm{mL}^{-1}$ ) were added to each well, and the mixture was incubated at $37^{\circ} \mathrm{C}$ for $2 \mathrm{~h}$. At the end of this period, the culture medium with the MTT excess was aspirated and after that, $100 \mu \mathrm{L}$ of DMSO were added to each well to dissolve the formazan crystals. ${ }^{20}$ The optical density (OD) of the wells was measured at $540 \mathrm{~nm}$ and compared to the control (cells with medium only). The data represent the mean of two experiments in triplicate and were expressed as means \pm standard deviation (SD). ${ }^{21}$ The concentration at which $50 \%$ survival of cells was observed $\left(\mathrm{IC}_{50}\right)$, the effective concentration causing 50\% decrease in cell viability $\left(\mathrm{EC}_{50}\right)$ and their $95 \%$ confidence intervals were determined from nonlinear regression using the program SigmaPlot version $11 .{ }^{22}$

\section{Results and Discussion}

The preliminary data found by the present method in the synthesis of norlapachol $\mathbf{4 g}$ showed a $95 \%$ yield, and resulted in patent filing. ${ }^{14}$ In this method, benzene was substituted by toluene, a greener and safer solvent with a higher boiling point. As far as we know, this remarkable result is better than any previously reported in the literature. For example, the classic Hooker's oxidative degradation of natural lapachol $\mathbf{1}$ to obtain norlapachol $\mathbf{4 g}$ results in yields 
around 50\%. ${ }^{16}$ Initially, we planned to use the inexpensive $n$-butyraldehyde as a model to observe the importance of some reaction conditions employed in original Kopanski methodology (Table 3), in particular the proportion of acetic acid/ $\beta$-alanine catalyst, the amount of aldehyde, the substitution of acetic acid by $p$-TsOH, and the substitution of $\beta$-alanine by triethylamine or L-proline (Table 3).

Table 3. Variation in conditions for the condensation of lawsone $\mathbf{2}$ with $n$-butyraldehyde
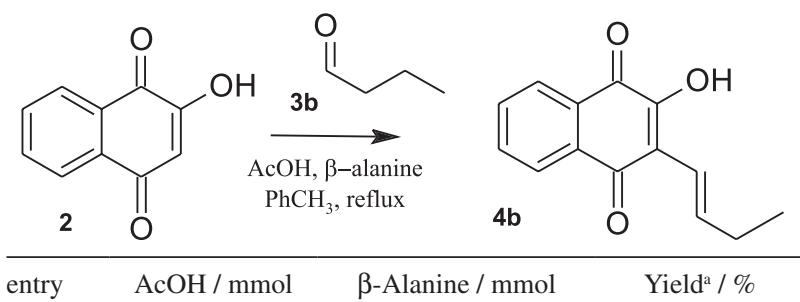

\begin{tabular}{lccc}
\hline entry & AcOH / mmol & $\beta$-Alanine / mmol & Yield $^{\mathrm{a}} \%$ \\
\hline 1 & 0.25 & - & 0 \\
2 & - & 0.28 & 23 \\
3 & 0.25 & 0.28 & 64 \\
4 & 0.50 & 0.28 & 62 \\
5 & 0.25 & 0.56 & 57 \\
6 & 0.25 & 0.28 & $35^{\mathrm{b}}$ \\
7 & 0.50 & 0.56 & 81 \\
8 & 1.00 & 1.12 & 50 \\
9 & 0.50 & 1.12 & 49 \\
10 & 1.00 & 0.56 & 67 \\
11 & - & 0.56 & $22^{\mathrm{c}}$ \\
12 & - & 0.56 & $28^{\mathrm{d}}$ \\
13 & 0.50 & - & $32^{\mathrm{e}}$ \\
\hline
\end{tabular}

asolated yield after chromatographic column; ${ }^{\mathrm{b}} 4 \mathrm{mmol}$ of $n$-butyraldehyde; ${ }^{\mathrm{c}} 0.5 \mathrm{mmol} \mathrm{N}(\mathrm{Et})_{3} ;{ }^{\mathrm{d}} 0.5 \mathrm{mmol} p$ - $\mathrm{TsOH} ;{ }^{\mathrm{e}} 0.56 \mathrm{mmol} \mathrm{L}$-proline. All reactions performed in $1 \mathrm{~h}$ reflux, using $40 \mathrm{~mL}$ of toluene in a Dean-Stark apparatus, and $2 \mathrm{mmol}$ of $n$-butyraldehyde.

From the data of Table 3, we conclude that the acetic acid or $\beta$-alanine alone were not effective as catalysts (entries 1 and 2), but the use of the mixture (entry 3 ) results in a good yield of $64 \%$. Increase of acid alone or $\beta$-alanine, however (entries 4 and 5 , respectively), did not contribute to further increase the observed yields. An increase of twofold in the aldehyde drops the yield (entry 6), probably caused by competition for self-condensation; however, the increase of catalyst in a 4:1:1 proportion of aldehyde:acetic acid: $\beta$-alanine results in the best yield of $81 \%$ (entry 7). Increasing two-fold the proportion of either catalyst or both (entries 8, 9 and 10) drops the observed yield. Changing the acetic acid by triethylamine or $p$-toluenesulfonic acid (entries 11 and 12) also drops the yield. The use of a known condensation catalyst L-proline (entry 13) was also unsuccesful. The reaction seems to be sensitive to the amount of acid and $\beta$-alanine, however, all the reactions with excess acid catalysis results in the formation of the bis-adduct dimer of lawsone, a polar product visible by TLC inspection that was studied in a previous article by our group. ${ }^{23}$ We chose to compare this modification of the original Kopanski procedure (named method A, entry 3), with this new method B (entry 9, Table 3 ) in a series of experiments conducted to verify the scope of the method with a range of suitable aldehydes. These results are shown in Table 4, and we planned to submit initially the available propionaldehyde (3a), $n$-butyraldehyde (3b), $n$-valeraldehyde (3c), phenylacetaldehyde (3e), $n$-hexanaldehyde (3p), isobutyraldehyde (3g), isovaleraldehyde (3i) and 2-ethylbutyraldehyde (3j) to condense with lawsone (2) using both conditions $\mathrm{A}$ and B that differ only by B using twice the amount of catalyst that A uses (Table 4). The best yields were obtained in either method for the more substituted alkyl, specially those with an extra alkyl at alpha position (see entries 6-8). This should reflect an easier elimination step at the formation of a more stable substituted double bond. This effect could be extended to the stabilization of the double bond by conjugation with a phenyl group (entry 4). The use of twice the amount of catalyst in method B should give better and more consistent yields without exceptions.

Table 4. Knoevenagel condensation reaction conditions and yields using methods A and B with suitable aldehydes

\begin{tabular}{llcccc} 
& & & & & \\
\hline
\end{tabular}

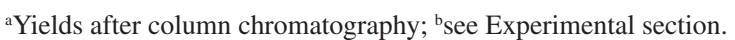


At a glance we could see that method B was generally better than the previous one, varying from an excelent yield of 95 and $96 \%$ for phenylaceltadehyde (3e) and 2-ethylbutyraldehyde (3j) (entries 4 and 8), respectively, to good yields $(85,86$ and $85 \%$ ) for isobutyraldehyde $(\mathbf{3 g})$, isovaleraldehyde (3i) and 2-phenyl-propionaldehyde (3q) (entries 6, 7 and 10), respectively. Linear alkyl aldehydes are also otained in good yields of 70 and $76 \%$, respectively, for $n$-valeraldehyde (3c) and $n$-hexanaldehyde (3p) (entries 3 and 9), representing better yields than those afforded using method $\mathrm{A}$. The 3-phenyl-propionaldehyde (3f) and even the cyclopentanone (3r) furnish modest yields of 47 and $36 \%$ (entries 5 and 11, Table 4), respectively, using method B. These last two precursors and 2-phenyl-propionaldehyde (3q) did not react (entries 5, 10 and 11) at the conditions used in method A by TLC inspection. However, the method did not improve the yield of propionaldehyde (3a), entry 1 . With the aid of some minor condition modifications, as the use of $\beta$-alanine alone as catalyst with $2 \mathrm{~h}$ reaction time, we are able to improve almost twice the yield of $\mathbf{3 a}$ to $31 \%$. We believe that the extremely low boiling point of propionaldehyde could explain the observed low yield. The compound 2-phenyl-propionaldehyde (3q) was only recently described and synthesized by the aid of a Pd-catalyzed hydroxyinvolved enolate-type reaction with lawsone and suitable alkenes. Previously, this type of functionalization of a 2-hydroxy-naphthoquinone used labor-intensive alkylation conditions ${ }^{24}$ or phenyliodonium ylides $\mathrm{BF}_{3}$ catalyzed cross coupling. ${ }^{25}$ Although Knoevenagel condensations with acyclic or cyclic ketones as enolates are common, ${ }^{26}$ it is noteworthy that in our report the cyclopentanone yielding compound $\mathbf{4 r}$ was used almost always as an electrophile, ${ }^{27}$ and as far as we know, this compound is new. The similar reaction with cyclohexanone gives no results with the sort of different modifications described before in this work.

The synthesis of the furan (10b) and pyran (11b) 3-hydroxymethyl-1,4-naphthoquinones were performed by the reaction of lapachol 1 or norlapachol $\mathbf{4 g}$ with paraformaldehyde in formic acid (Scheme 3), resulting in the condensation of the alkene quinone side chain and the formaldehyde by a Prins reaction, ${ }^{28,29}$ followed by in situ cyclization, in 76 and $51 \%$ yield, respectively. The corresponding acetates 10c and 11c were obtained by straightforward acetylation procedure in 86 and 54\% yield, respectively.

Concerning the biological activity, the title compounds $\mathbf{4 e}, \mathbf{4 i}, \mathbf{4 j}$, and $\mathbf{4 p}$ were previously tested together for antifungal activity, ${ }^{30} \mathbf{4 g}$ and $\mathbf{4 i}$ for molluscicidal activity, ${ }^{31,32} \mathbf{4 g}$ for antimycobacterial activity, ${ }^{33} 4 \mathbf{b}, 4 \mathrm{~g}$ and $4 \mathbf{i}$ for trypanocidal activity, ${ }^{34} \mathbf{4 g}$ and $\mathbf{4 i}$ for leishmanicial activity, ${ }^{35,36}$ and $\mathbf{4 e}$ was evaluated for cytotoxicity, ${ }^{37}$ antifungal ${ }^{30}$ and anticancer activities. ${ }^{24}$ Although the majority of the title compounds were known and tested elsewhere, they were all tested together in the present study for cytotoxic screening against tumor cell lines HEP-2, MCF-7 and NCI-H292 (Table 5).

Concerning the inhibition of growth of HEP-2 tumor cells, the compounds alkenyl-1,4-naphthoquinone series $\mathbf{4 b}, \mathbf{4 c}, \mathbf{4 i}, \mathbf{4 j}, \mathbf{4 p}$ and $\mathbf{4 q}$ showed the highest percentuals of inhibition, superior to those from lapachol $\mathbf{1}$ and reference compound doxorubicin (Table 5). Compound $\mathbf{4 c}$ showed a higher percentual of inhibition (95.6\%) against (HEP-2) cell lines when compared to $\mathbf{4 j}$ with $94.1 \%, \mathbf{4 p}$ with $94 \%$, 4b with $93.5 \%$, $\mathbf{4 i}$ with $93 \%$ and $\mathbf{4 q}$ with $91.2 \%$. In this series the norlapachol $\mathbf{4 g}$ showed the lowest inhibition percentual (27.3\%) (Table 5). Concerning the MCF-7 cell line tested the only compound with high activity was 4j with $77.9 \%$ inhibition, showing a better profile than the isomer with a linear alkyl side chain $\mathbf{4 p}$ with $53.6 \%$ inibition (Table 5). Notably, in these experimental trials the compound norlapachol $\mathbf{4 g}$ did not inhibit the growth of MCF-7 cells or of NCI-H292. In NCI-H292, the highest inhibition for the alkenyl-1,4-naphthoquinones 4 were 85.9, 85.7 and $85.3 \%$ for compounds $\mathbf{4 i}, \mathbf{4 j}$ and $\mathbf{4 r}$, respectively (Table 5). The presence of an additional phenyl ring in compounds $\mathbf{4 e}, \mathbf{4 f}$ and $\mathbf{4 q}$ did not improve the biological profile. From the data on Table 5 we could see that the series of alkenyl-1,4-naphthoquinones $\mathbf{4}$ showed a remarkable selectivity to the larynx tumor cell lines, when compared to other tumor cell lines.

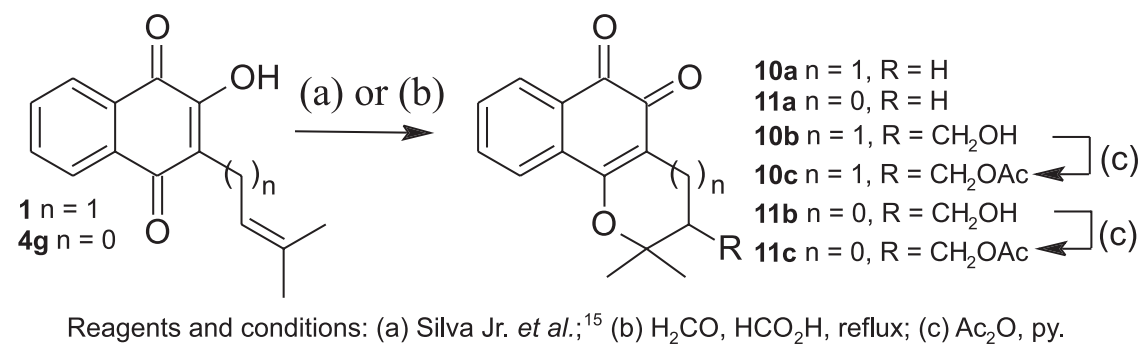

Scheme 3. The synthesis of the furan (10b) and pyran 3-hydroxymethyl-1,4-naphthoquinones (11b) and corresponding acetates 10c and 11c from lapachol (1) and norlapachol 4g. 
Table 5. Cell growth inhibition percentual of the 3-alkenyl-2-hydroxy1,4-naphthoquinones (4) and cyclic derivatives 10a-c and 11a-c at $25 \mu \mathrm{g} \mathrm{mL}^{-1}$ in the three tumor cell lines

\begin{tabular}{lccc}
\hline Compound & HEP-2 $/ \%$ & MCF-7 $^{\mathrm{a}} / \%$ & NCI-H292 $/ \%$ \\
\hline Doxorubicin & $86.6 \pm 3.5$ & $59.5 \pm 1.7$ & $92.9 \pm 1.5$ \\
$\mathbf{1}$ & $90.8 \pm 2.8$ & $50.8 \pm 4.5$ & $59.8 \pm 4.2$ \\
$\mathbf{4 a}$ & $62.8 \pm 5.2$ & $55.2 \pm 7.3$ & $26.2 \pm 5.3$ \\
$\mathbf{4 b}$ & $93.5 \pm 0.1$ & $26.1 \pm 1.9$ & $79.8 \pm 1.7$ \\
$\mathbf{4 c}$ & $95.6 \pm 1.5$ & $46.3 \pm 1.4$ & $81.7 \pm 3.4$ \\
$\mathbf{4 e}$ & $84.5 \pm 1.5$ & $57.5 \pm 1.8$ & $80.6 \pm 0.8$ \\
$\mathbf{4 f}$ & $85.0 \pm 1.4$ & $58.9 \pm 1.0$ & $78.7 \pm 1.9$ \\
$\mathbf{4 g}$ & $27.3 \pm 1.8$ & $0.0 \pm 0.0$ & $0.0 \pm 0.0$ \\
$\mathbf{4 i}$ & $93.0 \pm 0.5$ & $5.1 \pm 1.4$ & $85.9 \pm 0.3$ \\
$\mathbf{4 j}$ & $94.1 \pm 0.0$ & $77.9 \pm 3.5$ & $85.7 \pm 2.3$ \\
$\mathbf{4 p}$ & $94.0 \pm 2.0$ & $53.6 \pm 5.7$ & $83.3 \pm 0.3$ \\
$\mathbf{4 q}$ & $91.2 \pm 0.5$ & $50.8 \pm 0.9$ & $63.3 \pm 1.4$ \\
$\mathbf{4 r}$ & $86.8 \pm 0.1$ & $41.6 \pm 3.4$ & $85.3 \pm 1.2$ \\
$\mathbf{1 0 a}$ & $96.0 \pm 1.1$ & $96.9 \pm 0.3$ & $95.0 \pm 2.9$ \\
$\mathbf{1 0 b}$ & $97.6 \pm 0.8$ & $98.5 \pm 0.0$ & $98.2 \pm 1.3$ \\
$\mathbf{1 0 c}$ & $99.0 \pm 0.8$ & $98.4 \pm 0.4$ & $96.8 \pm 2.3$ \\
$\mathbf{1 1 a}$ & $98.8 \pm 0.2$ & $98.7 \pm 0.5$ & $97.6 \pm 0.0$ \\
$\mathbf{1 1 b}$ & $97.4 \pm 0.9$ & $94.7 \pm 5.5$ & $97.7 \pm 1.8$ \\
$\mathbf{1 1 c}$ & $94.4 \pm 3.8$ & $96.1 \pm 0.1$ & $92.7 \pm 1.7$ \\
\hline
\end{tabular}

anhibitory concentration percentage $(\mathrm{IC} \%) \pm$ standard deviation. HEP-2: human larynx carcinoma cell line; MCF-7: breast adenocarcinoma cell line; NCI-H292: human lung carcinoma cell line.

A very different scenario is obtained when the cyclized derivatives 10a-c and 11a-c were compared with the open chain alkenyl 1,4-naphthoquinones $\mathbf{4}$, with all compounds showing excellent profiles of inhibition, ranging from $99 \%$ for 10c in HEP-2 cell lines to $92.7 \%$ for 11c in NCI-H292 cell lines. The acetylation of the hydroxymethyl groups enhances the observed activities in all tested cell lines, either in pyran $\mathbf{1 0 b}$ or furan $\mathbf{1 1 b}$ series (Table 5).

In order to determine the half maximal inhibitory concentration $\left(\mathrm{IC}_{50}\right)$ values $(\mu \mathrm{M})$ displayed in Table 6 , we decided to adopt a threshold for using only compounds with at least $75 \%$ inhibition in all cell lines tested (at $25 \mathrm{mg} \mathrm{mL}^{-1}$ concentration). Thus, compounds $4 \mathbf{j}$, 10a-c and 11a-c are those satisfying this criterion as can be observed from the data in Table 5. The 3-alkenyl-2-hydroxy1,4-naphthoquinone compound $\mathbf{4} \mathbf{j}$ was shown to be the least cytotoxic for all tested cell lines (Table 6). For the MCF-7 tumor cell line, compounds 11a-c were more active than 10a-c, $\beta$-nor-lapachone (11a) being more cytotoxic than 11b, 11c, and even more cytotoxic than the positive control. All tested cyclized compounds showed a remarkable citotoxic profile against the breast MCF-7 tumor cell line, ranging from $0.10 \mu \mathrm{M}$ for $\mathbf{1 1 a}$ to $5.51 \mu \mathrm{M}$ for $\mathbf{1 0 b}$. Also in this tumor cell line, the hydroxymethyl $\mathbf{1 0 b} / \mathbf{1 1} \mathbf{b}$ and acetate derivatives 10c/11c resulted in decreased cytotoxicity when compared to the parent compounds $\beta$-lapachone (10) and $\beta$-nor-lapachone (11), although 10c did not result in changes to the observed activity (Table 6). The tumor cell lines NCI-H292 and HEP-2 showed more sensitivity to the acetylated derivative 10c, with $\mathrm{IC}_{50}$ of 2.26 and $6.81 \mu \mathrm{M}$, respectively, and also for the less active $11 \mathrm{c}$, with $\mathrm{IC}_{50}$ values of 11.13 and $13.6 \mu \mathrm{M}$, respectively. In general, the tested compounds showed remarkable and consistent cytotoxicity in tested cancer cell lines, although the compounds presented high inhibitory effect in the growth of Buffalo green monkey kidney (BGMK) cells used to access the selectivity, which means a non-selective effect and high

Table 6. Cytotoxic activity expressed as $\mathrm{IC}_{50}$ of compounds $\mathbf{4 j}$, $\mathbf{1 0 a - c}$ and $\mathbf{1 1 a - c}$ against tumor cell lines

\begin{tabular}{|c|c|c|c|c|}
\hline \multirow{2}{*}{ Compound } & \multicolumn{4}{|c|}{ Cell line $\mathrm{IC}_{50} / \mu \mathrm{M}$} \\
\hline & MCF-7 & NCI-H292 & HEP-2 & BGMK \\
\hline $4 j$ & $18.75(16.01-22.26)$ & $15.62(12.5-20.31)$ & ND & ND \\
\hline $10 \mathrm{a}$ & $2.72(2.02-3.71)$ & $17.68(12.56-24.87)$ & $11.69(9.33-14.62)$ & $8.26(7.35-9.54)$ \\
\hline $10 \mathrm{~b}$ & $5.51(4.81-6.47)$ & $14.48(9.70-21.54)$ & $14.63(12.20-17.57)$ & $4.55(3.12-6.65)$ \\
\hline $10 \mathrm{c}$ & $2.73(2.61-2.83)$ & $2.26(5.95-7.13)$ & $6.81(5.89-7.86)$ & $6.21(4.84-7.92)$ \\
\hline 11a & $0.10(0.07-0.15)$ & $12.28(10.70-14.07)$ & $10.74(10.04-11.53)$ & $4.78(3.33-6.92)$ \\
\hline $11 b$ & $0.46(0.38-0.62)$ & $11.27(9.37-13.56)$ & $13.25(9.72-18.06)$ & $9.18(4.76-17.59)$ \\
\hline $11 \mathrm{c}$ & $0.60(0.5-0.7)$ & $11.13(10.03-12.36)$ & $13.60(11.63-15.93)$ & $5.83(5.3-6.4)$ \\
\hline Doxorubicin & $0.36(0.18-0.44)$ & $0.36(0.18-0.92)$ & $1.28(0.55-2.57)$ & $>46.04$ \\
\hline Cisplatin & ND & ND & ND & $8.10(6.26-10.43)$ \\
\hline
\end{tabular}

Data are presented as half maximal inhibitory concentration $\left(\mathrm{IC}_{50}\right)$ values and $95 \%$ confidence intervals obtained by nonlinear regression for all cell lines. Doxorubicin was used as positive control. Only compounds with an $\mathrm{IC}_{50}$ value lower than $5 \mu \mathrm{g} \mathrm{mL}^{-1}$ for at least one cell line were considered active. MCF-7: breast adenocarcinoma cell line; NCI-H292: human lung carcinoma cell line; HEP-2: human larynx carcinoma cell line; BGMK: Buffalo green monkey kidney cell line; ND: not determined. 
cytoxicity for the series tested, except for the series of cyclic furan-1,4-naphthoquinone and 3-hydroxymethyl derivatives 11a-c, which showed a good selectivity index for MCF-7.

\section{Conclusions}

In this work a very efficient Knoevenagel procedure was presented for the obtention of 2-hydroxy-3-alkenyl1,4-naphthoquinones (4) from lawsone (2) and suitable aldehydes, using $\beta$-alanine and acetic acid as catalysts. The method runs with overall good yields in a systematic fashion. Some of the parameters briefly studied here could be easily altered resulting in improved reaction yields, especially when using non-linear chain aldehydes. We also presented the synthesis of a series of furan and pyranderived hydroxymethyl-1,4-naphthoquinones obtained by an acid catalyzed Prins cyclization of lapachol and norlapachol and corresponding acetyl derivatives. The 2-hydroxy-3-alkenyl-1,4-naphthoquinone (4) series was in general less cytotoxic than the cyclized furan- and pyrannaphthoquinones 10/11. The $\beta$-nor-lapachone (11a) was the most active compound in the MCF-7 tumor cell line. In general, the furan- ( $\beta$-nor-lapachone) (11) derivatives were more active than pyran- $\beta$-lapachone (10), and the presence of the hydroxyl and acetate groups decreased the cytotoxicity of $\beta$-lapachone and $\beta$-nor-lapachone. Also the 2-(2-ethyl-but1-enyl)-3-hydroxy-[1,4]naphthoquinone (4j) was shown to be the less cytotoxic for all tumor cell lines tested.

\section{Supplementary Information}

Supplementary information is available free of charge at http://jbcs.sbq.org.br as PDF file.

\section{Acknowledgments}

The authors thank CAPES, CNPq and FACEPE (PRONEM APQ 0741.11.06/14) for financial support, and the Central Analítica of DQF-UFPE and CENAPESQUFRPE for the use of facilities. C. A. C. thanks Eduardo J. Oliveira (UFVJM) for useful suggestions.

\section{References}

1. Gomes, S. L. S.; Militão, G. C. G.; Costa, A. M.; Pessoa, C. O.; Costa-Lotufo, L. V.; Cunha-Junior, E. F.; Torres-Santos, E. C.; Costa, P. R. R.; da Silva, A. J. M.; J. Braz. Chem. Soc. 2017, $28,1573$.

2. de Oliveira, R. N.; da Silva, M. G.; da Silva, M. T.; Melo, V. N.; Valença, W. O.; da Paz, J. A.; Camara, C. A.; J. Braz. Chem. Soc. 2017, 28, 681 .
3. Brandão, G. C.; Missias, F. C. R.; Arantes, L. M.; Soares, L. F.; Roy, K. K.; Doerksen, R. J.; de Oliveira, A. B.; Pereira, G. R.; Eur. J. Med. Chem. 2018, 145, 191.

4. Hooker, S. C.; J. Am. Chem. Soc. 1936, 58, 1163.

5. Bock, K.; Jacobsen, N.; Terem, B.; J. Chem. Soc., Perkin Trans. 1 1986, 659.

6. Ferreira, V. F.; Coutada, L. C.; Pinto, M. C. F. R.; Pinto, A. V.; Synth. Commun. 1982, 12, 195.

7. Kopanski, L.; Karbach, D.; Selbitschka, G.; Steglich, W.; Liebigs Ann. Chem. 1987, 793.

8. Gilles, R. G. F.; Roos, G. H. P.; Tetrahedron Lett. 1975, 47, 4159.

9. Ameer, F.; Giles, R. G. F.; Green, I. R.; Pearce, R.; Synth. Commun. 2004, 34, 1247.

10. Lee, Y. R.; Choi, J. H.; Trinh, D. T. L.; Kim, N. W.; Synthesis 2005, 18, 3026.

11. Anufriev, V. F.; Chizhova, A. Y.; Denisenko, V. A.; Novikov, V. L.; Russ. J. Org. Chem. 1993, 29, 1671.

12. Glazunov, V. P.; Berdyshev, D. V.; Yakubovskaya, A. Y.; Porkhilo, N. D.; Russ. J. Org. Chem. 2006, 55, 1729.

13. Nagabhushana, K.; Ameer, F.; Green, I. R.; Synth. Commun. 2001, 31, 719.

14. Pinheiro, S. M.; Silva, T. M. S.; Camara, C. A.; Br PI 102012 019793-6 A2 2015.

15. Silva Jr., E. N.; Souza, M. C.; Pinto, A. V.; Pinto, M. C.; Goulart, M. O.; Barros, F. W.; Pessoa, C.; Costa-Lotufo. L. V.; Montenegro, R. C.; Moraes, M. O.; Ferreira, V. F.; Bioorg. Med. Chem. 2007, 15, 7035.

16. Fieser, L. F.; Fieser, M.; J. Am. Chem. Soc. 1948, 70, 3215.

17. Oliveira, A. B.; Raslan, D. S.; Khuong-Huu, F.; Tetrahedron Lett. 1990, 31, 6873.

18. Wang, N.; Wu, X.; Qin, T.; Zhou, J.; You, Q.; Zhang, X.; RSC Adv. 2016, 6, 104126.

19. Alley, M. C.; Scudiero, D. A.; Monsk, A.; Hursey, M. I.; Czerwinski, M. J.; Fine, D. L.; Abbott, B. J.; Mayo, J. G.; Shoemaker, R. H.; Boyd, M. R.; Cancer Res. 1988, 48, 589.

20. Mosmann, T.; J. Immunol. Methods 1983, 16, 55.

21. Berridge, M. V.; Tan, A. S.; McCoy, K. D.; Wang, R.; Biochemica 1996, 4, 14.

22. Systat Software; SigmaPlot version 11; Systat Software, San Jose, CA, USA, 2008.

23. Araújo, M. V.; Souza, P. S. O.; Queiroz, A. C.; Matta, C. B. B.; Leite, A. B.; Silva, A. E.; França, J. A. A.; Silva, T. M. S.; Camara, C. A.; Alexandre-Moreira, M. S.; Molecules 2014, 19, 15180.

24. Fiorito, S.; Epifano, F.; Bruyere, C.; Mathieu, V.; Kiss, R.; Genovese, S.; Bioorg. Med. Chem. Lett. 2014, 24, 454.

25. Malamidou-Xenikaki, E.; Tsanakopoulou, M.; Chatzistefanou, M.; Litina, D. H.; Tetrahedron 2015, 71, 5650.

26. Chinchkar, S. M.; Patil, J. D.: Korade, S. N.; Gokavi, G. S.; Shejawal, R. V.; Pore, D. M.; Lett. Org. Chem. 2017, 14, 403. 
27. Ce, S.; Zhen-Chu, C.; Qin-Guo, Z.; Synthesis 2003, 555.

28. Camara, C. A.; Pinto, A. C.; Vargas, M. D.; ZukermanSchpector, J.; Tetrahedron 2002, 58, 6135.

29. Barbosa, T. P.; Camara, C. A.; Silva, T. M. S.; Martins, R. M.; Pinto, A. C.; Vargas, M. D.; Biorg. Med. Chem. Lett. 2005, 13, 6464.

30. Jacobsen, N.; Wengel, A.; Pestic. Sci. 1986, 17, 686.

31. Santos, A. F.; Ferraz, P. A. L.; Pinto, A. V.; Pinto, M. C. F. R.; Goulart, M. O. F.; Sant'Ana, A. E. G.; Int. J. Parasitol. 2000, 30, 1199.

32. Lima, N. M. F.; Santos, A. F.; Porfírio, Z.; Goulart, A. O. F.; Sant'Ana, A. E. G.; Acta Trop. 2002, 83, 43.

33. Carneiro, P. F.; Pinto, M. C. F. R.; Coelho, T. S.; Cavalcanti, B. C.; Pessoa, C.; de Simone, C. A.; Nunes, I. K. C.; de Oliveira, N. M.; de Almeida, R. G.; Pinto, A. V.; de Moura, K. C. G.; da Silva, P. A.; da Silva Jr., E. N.; Eur. J. Med. Chem. 2011, 46, 4521.
34. Souza, N. B.; Andrade, I. M.; Carneiro, P. F.; Jardim, G. A. M.; Melo, I. M. M.; Silva, E. N.; Krettli, A. U.; Mem. Inst. Oswaldo Cruz, 2014, 109, 546.

35. Guimarães, T. T.; Pinto, M. C. F. R.; Lanza, J. S.; Melo, M. N.; Monte-Neto, R. L.; Melo, I. M. M.; Diogo, E. B. T.; Ferreira, V. F.; Camara, C. A.; Valença, W. O.; Oliveira, R. N.; Frézard, F.; Silva Jr., E. N.; Eur. J. Med. Chem. 2013, 63, 523.

36. Lima, N. M. F.; Correia, C. S.; Leon, L. L.; Machado, G. M. C.; Madeira, M. F.; Santana, A. E. G.; Goulart, M. O. F.; Mem. Inst. Oswaldo Cruz 2004, 99, 757.

37. Cushion, M. T.; Chen, F.; Kloepfer, N.; Antimicrob. Agents Chemother. 1997, 41, 379.

Submitted: April 14, 2018

Published online: July 31, 2018 